Abstracta Iranica

Revue bibliographique pour le domaine irano-aryen

Volume 34-35-36 | 2017

Comptes rendus des publications de 2011-2013

\title{
F. Milani. Words, not swords: Iranian women writers and the freedom of movement.
}

\section{Laetitia Nanquette}

\section{OpenEdition}

1 Journals

\section{Édition électronique}

URL : http://journals.openedition.org/abstractairanica/41374

DOI : 10.4000/abstractairanica.41374

ISSN : 1961-960X

Éditeur :

CNRS (UMR 7528 Mondes iraniens et indiens), Éditions de l'IFRI

Référence électronique

Laetitia Nanquette, «F. Milani. Words, not swords: Iranian women writers and the freedom of movement. », Abstracta Iranica [En ligne], Volume 34-35-36 | 2017, document 3, mis en ligne le 15 juillet 2016, consulté le 01 octobre 2020. URL : http://journals.openedition.org/abstractairanica/41374; DOI : https://doi.org/10.4000/abstractairanica.41374

Ce document a été généré automatiquement le 1 octobre 2020.

Tous droits réservés 


\title{
F. Milani. Words, not swords: Iranian women writers and the freedom of movement.
}

\author{
Laetitia Nanquette
}

\section{RÉFÉRENCE}

F. Milani, Words, not swords: Iranian women writers and the freedom of movement. Syracuse, N.Y., Syracuse University Press, 2011, 345 p.

1 Cet ouvrage étudie l'héritage de la ségrégation des sexes en Iran et ses manifestations dans la littérature et le cinéma iraniens. Milani s'intéresse à la façon dont la liberté de mouvement, au-delà de la dichotomie voilée/non-voilée, permet aux femmes d'accéder aux centres de pouvoir, d'exercer leurs droits et de faire entendre leur voix littérairement. Le voile n'est plus essentiel pour comprendre la ségrégation des femmes, contrairement à l'argument de son premier livre, Veils and words: the emerging voices of Iranian women writers (1992).

2 Un chapitre d'introduction présente l'histoire du voile féminin à travers le monde, insistant sur le fait que le voile est un moyen de contraindre non seulement le corps mais aussi la voix des femmes dans leur mouvement social. Milani démontre que la liberté de mouvement des femmes est un sujet central dans bien des cultures et des pays, comparant par exemple le voile en Islam et le bandage des pieds en Chine.

3 La première partie de l'ouvrage étudie les implications sociales, littéraires et esthétiques du confinement des femmes dans la littérature et le cinéma iranien. La deuxième partie célèbre les œuvres d'auteurs comme Ṭāhere Qurratul'ayn, Forūg g FarroḨzād, Sīmīn Behbahānī et Šahrnūš Pārsīpūr. La dernière partie étudie les mémoires des iraniennes-américaines, notamment ces " narrations de captivité » qui ont fleuri sur le marché littéraire américain dans les années 2000 et propagé des stéréotypes sur la femme iranienne comme victime et opprimée. 
4 Comme dans son premier livre, Veils and words, dont elle réfute en partie la thèse, Milani propose une étude personnelle de la littérature iranienne féminine. Bien que s'attachant à des œuvres et auteurs canoniques, elle offre une lecture riche en faisant des comparaisons nouvelles. Cet ouvrage est également lisible par un lectorat large, de même qu'il peut intéresser les activistes féministes.

\section{AUTEURS}

\section{LAETITIA NANQUETTE}

University of New South Wales, Sydney 